
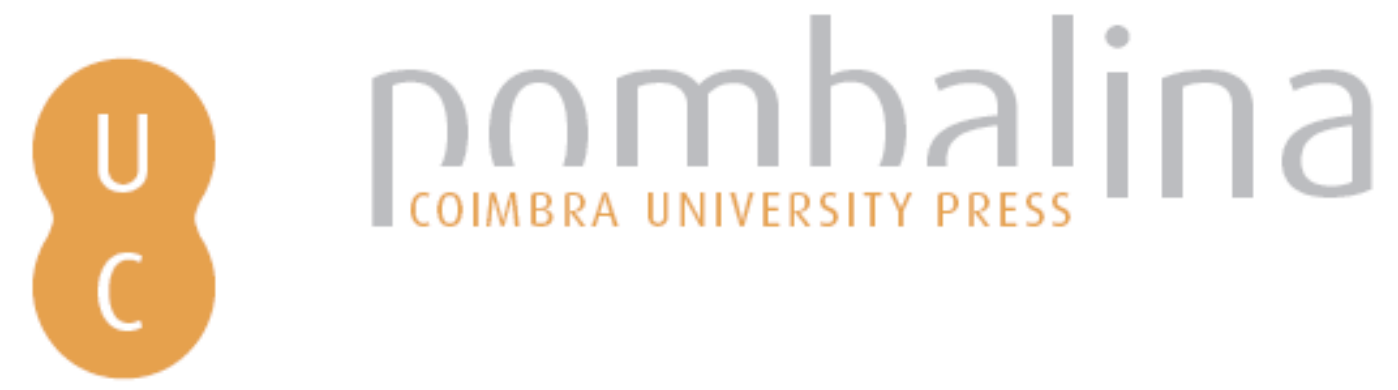

\title{
Para que não se confunda a gestão do plágio estudantil com questões de ética, fraude e ludíbrio: o que nos ensina a experiência do Ensino Superior Europeu
}

\author{
Autor(es): $\quad$ Carroll, Jude
}

Publicado por: Imprensa da Universidade de Coimbra

URL

persistente: URI:http://hdl.handle.net/10316.2/38807

DOI: $\quad$ DOI:http://dx.doi.org/10.14195/978-989-26-1123-5_3

Accessed : $\quad$ 26-Apr-2023 13:55:49

A navegação consulta e descarregamento dos títulos inseridos nas Bibliotecas Digitais UC Digitalis, UC Pombalina e UC Impactum, pressupõem a aceitação plena e sem reservas dos Termos e Condições de Uso destas Bibliotecas Digitais, disponíveis em https://digitalis.uc.pt/pt-pt/termos.

Conforme exposto nos referidos Termos e Condições de Uso, o descarregamento de títulos de acesso restrito requer uma licença válida de autorização devendo o utilizador aceder ao(s) documento(s) a partir de um endereço de IP da instituição detentora da supramencionada licença.

Ao utilizador é apenas permitido o descarregamento para uso pessoal, pelo que o emprego do(s) título(s) descarregado(s) para outro fim, designadamente comercial, carece de autorização do respetivo autor ou editor da obra.

Na medida em que todas as obras da UC Digitalis se encontram protegidas pelo Código do Direito de Autor e Direitos Conexos e demais legislação aplicável, toda a cópia, parcial ou total, deste documento, nos casos em que é legalmente admitida, deverá conter ou fazer-se acompanhar por este aviso.

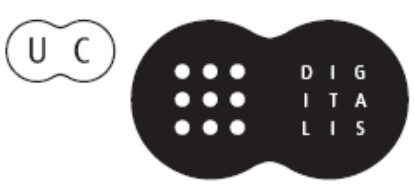




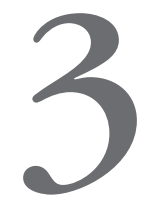

PARA QUE NÃo SE CONFUNDA A GESTÃo DO PLÁGIO ESTUdANTIL COM QUESTÕES DE ÉTICA, FRAUDE E LUDÍBRIO:

\section{O QUE NOS ENSINA A EXPERIÊNCIA DO ENSINO SUPERIOR EUROPEU}

Jude Carroll

Consultora em desenvolvimento educativo

bttp://dx.doi.org/10.14195/978-989-26-1123-5_3 
(Página deixada propositadamente em branco.) 


\subsection{Introdução}

É crescente, um pouco por toda a Europa, o interesse pelo plágio estudantil e pela sua gestão nas instituições de ensino superior, porventura fomentado pelo recurso também crescente às tarefas da componente letiva (por vezes designadas trabalhos escritos, ou simplesmente 'trabalhos', ou ainda avaliação fora da aula). O plágio começa a ser encarado como algo de importante a partir do momento em que o trabalho produzido pelos estudantes se traduz em notas e em créditos. Essa tomada de consciência é também frequentemente desencadeada pelo uso crescente do inglês. Estes são fatores passíveis de conduzir à adoção de medidas em universidades que ainda não tenham criado ou aplicado políticas de gestão do plágio. Tem-me igualmente sido possível observar que essa preocupação crescente está a fazer com que certas instituições, em que as políticas já foram criadas mas ficaram na prateleira, estejam agora, finalmente, a passar à prática. As universidades que até agora não encararam o plágio estudantil como uma prioridade precisam de o fazer, e o presente capítulo propõe-se ajudá-las a caminhar nessa direção.

Começarei por definir plágio, ludíbrio e fraude, refletindo com algum pormenor sobre aquilo que cada um destes termos quer dizer e também sobre o que não quer dizer. O leitor poderá achar esta minha reflexão despropositada - será que quem concebe e quem aplica as políticas precisa mesmo de pensar a definição de plágio e de ludíbrio com todo este pormenor? Porém a experiência ensinou-me que é geral a confusão existente em torno destes três conceitos, e que, quando ela existe, os mal-entendidos são passíveis de travar 
ou desviar os esforços no sentido da sua gestão eficaz. Um equívoco comum é considerar que todo o plágio constitui ludíbrio, ou 'batota'

De seguida farei o elenco dos aspetos que constituem uma política eficaz e eficiente de gestão do plágio estudantil, baseando-me para isso principalmente em bibliografia do contexto universitário anglófono. Enunciarei também alguns procedimentos para lidar com os casos de possível ocorrência de plágio, ludíbrio e fraude estudantis. O objetivo é a elaboração de políticas realistas e a concretização de procedimentos que sejam justos, defensáveis e coerentes na sua aplicação. Dos procedimentos, uma vez adotados, exige-se que sejam capazes de gerir quantidades relativamente elevadas de casos, que constituam um elemento normal da rotina académica, que sejam aplicados por um corpo docente já de si muito ocupado, que sejam sustentáveis num momento em que as universidades tanto carecem de recursos, e que consigam competir com inúmeras outras prioridades institucionais. Um conjunto bem exigente de condições, portanto.

Para melhor poder apoiar as instituições na adoção de políticas e procedimentos eficazes, o artigo termina com uma descrição do sistema do ACO - Academic Conduct Officer ${ }^{8}$. O sistema já se encontra em vigor em muitas universidades de todo o mundo e tenho conhecimento de que a cada dia há inúmeras outras a adotá-lo. Ao cabo de mais de uma década de utilização e avaliação, o sistema ACO (ou algo equivalente) deu provas de ser uma componente eficaz da gestão holística dos fenómenos de plágio e ludíbrio estudantis. Possuir ACOs, por si só, não resolve problema nenhum. A introdução do sistema é, por norma, acompanhada de procedimentos em que tanto docentes como estudantes confiam, que entendem e que veem que se poderão traduzir em penalizações justas e coerentes em caso de infração dos regulamentos académicos. Tenho verificado, por parte dos docentes, uma resistência

7 Em inglês, cheating. [N.T.]

8 Gabinete, ou responsável, para a conduta académica. [N.T.] 
cada vez menor a lidar com a gestão do plágio. A conclusão que daí retiro é que a utilização de um sistema como o ACO poderá funcionar como catalisador para uma aposta crescente nessa gestão.

\subsection{Distinções necessárias}

Defendo, como ponto de partida, que gerir o plágio na universidade é diferente de ter de o fazer fora dela. No seio da universidade o plágio deve ser encarado, fundamentalmente, como um problema do âmbito da aprendizagem. O plágio e a aprendizagem interligam-se de duas maneiras:

Problema de aprendizagem 1.) A maioria das universidades europeias rege-se por teorias da aprendizagem vulgarmente designadas por construtivistas. A teoria construtivista da aprendizagem parte do pressuposto de que o estudante não aprende apenas quando se defronta com, recolhe, ou replica ideias; ele aprende quando as compreende por si próprio e as domina. Do estudante que se rege por um paradigma construtivista da aprendizagem ou que trabalha em ambiente de investigação espera-se que aplique os conhecimentos adquiridos, dando mostras de que os domina. É através da utilização das ideias e da sua transformação que o estudante faz prova de que apreende. Compete-lhe igualmente ir beber às ideias de outrem para assim construir os seus argumentos e/ou achar soluções para os problemas. O plágio, enquanto algo que implica copiar, apropriar-de de, ou reciclar as ideias de outrem, rompe a conexão existente entre o esforço laborioso' ${ }^{9}$ a aprendizagem, e os créditos ou outro benefício académico.

\footnotetext{
9 O 'esforço laborioso' a que me refiro consiste na utilização e na devida sinalização, de uma maneira transparente, do trabalho de outros. Trata-se de uma forma de proceder que está longe de ser fácil ou óbvia, e que não é gerida do mesmo modo de uma universidade para outra.
} 
Problema de aprendizagem 2.) O estudante precisa de aprender a utilizar e a valorizar as convenções e as práticas pedagógicas em vigor no seio das universidades. Quando chega à universidade, a maior parte dos estudantes não traz consigo o conhecimento e as competências necessários para compreender e acatar os regulamentos e as exigências inerentes à integridade académica.

O lugar fulcral que a aprendizagem ocupa na gestão do plágio estudantil significa que há que continuar a centrar a atenção nas questões da acreditação e da garantia de qualidade. As universidades devem evitar deixar-se influenciar excessivamente pelo debate público em torno do plágio, tão comum entre jornalistas e comentadores, e tão inflamado e viciado por vezes. Fora do contexto universitário, a presunção de que o plágio implica sempre fazer juízos morais acerca da pessoa que plagia pode ou não ter cabimento (pessoalmente tenho, sobre o tema, ideias assentes, que no entanto saem do escopo deste artigo). No interior da universidade, associar o plágio a integridade revela-se, as mais das vezes, inadequado. A tentativa de compreender a lógica das infrações estudantis aos regulamentos tem, frequentemente, muito menos a ver com juízos sobre o perfil moral dos estudantes do que com o facto de estes não terem ainda interiorizado a cultura da universidade e das suas normas e de ainda não terem adotado as convenções universitárias relativas à utilização e devida sinalização do trabalho alheio (Blum, 2007; Sutherland-Smith, 2010).

\subsubsection{Distinção entre plágio e ludíbrio}

De entre as definições de plágio prefiro a de Teddi Fishman, Diretora do Centro Internacional para a Integridade Académica, sediado nos EUA. Segundo Fishman, o plágio ocorre quando alguém: 
- apresenta trabalho(s) ...

- de uma fonte nomeada ou identificável ...

- numa situação em que se espera trabalho original ...

- sem que haja uma suficiente sinalização da fonte ...

- para obtenção de créditos ou outro benefício próprio (Fishman, 2009).

Repare-se que, apesar de o nome do Centro de Fishman aludir a integridade, o mesmo não sucede com a definição de plágio proposta pela autora. Com efeito, a definição de Fishman fixa cinco condições que terão, todas elas, de estar presentes para que se possa responder à pergunta: Este trabalho contém plágio? Um trabalho que ostente alguns dos critérios mas não a sua totalidade não poderá ser considerado plágio. Assim, e por exemplo, poderá dar-se a circunstância de um estudante apresentar, para efeito de obtenção de créditos, material copiado, mas numa situação em que a originalidade ${ }^{10}$ não constitua um requisito. Será esse o caso, por exemplo, de um professor que dê como trabalho de casa uma pergunta de natureza factual ('De que modo é que o pâncreas contribui para o metabolismo do açúcar?'), quando a resposta consta do manual de apoio do curso. Se o estudante apresentar um trabalho de casa copiado do manual, ter-se-á tratado, em minha opinião, de uma má prática da parte do docente que ordenou a tarefa, da qual pouca ou nenhuma aprendizagem advirá, provavelmente, para o estudante. Contudo o trabalho por este apresentado não constitui, em si mesmo, plágio. E o motivo por que não é plágio é que estamos perante uma situação em que não se exige originalidade, além de que o trabalho finalmente apresentado (i.e., a resposta) não é algo que seja pertença de uma pessoa ou de uma fonte identificada. $O$ trabalho poderia ser

\footnotetext{
10 Note-se que a palavra 'original' não pretende designar um produto novo, exclusivo daquele aluno, ou algo de inteiramente inaudito, mas tão somente referir o ato que lhe deu origem. Ou seja, o que está em causa é o produto resultante do pensamento, esforço e ação do estudante.
} 
melhorado se fornecesse a referência bibliográfica, revelando a autoridade da fonte e a eventual atualidade da publicação que contém a resposta; tal permitiria que o docente verificasse o grau de rigor, etc. - mas essa é uma outra questão.

Eis outro exemplo de um trabalho que preenche alguns mas não todos os requisitos para que possa ser considerado plágio: Um estudante de doutoramento usa os dados e as ideias de alguém que não identifica, transcrevendo uma sequência de dez ou doze palavras do original em que a ideia vinha expressa, mas sem chegar, propriamente, a indicar a referência bibliográfica no corpo do texto - como por exemplo (Wilson, 1998: 32). No entanto, o doutorando menciona Wilson na sua tese, deixando claro que é a esta autora a que se devem as ideias e referindo-se, inclusivamente, à época em que a obra foi publicada ('...há mais de dez anos'). Ora esta utilização da obra de Wilson é inaceitável numa tese de doutoramento, porém não configura plágio, uma vez que foi sinalizada. A utilização correta traria um acréscimo de qualidade e, neste caso concreto, haveria que usar aspas e uma referência efetiva para mostrar que o autor da dissertação é competente no uso que faz das palavras alheias. Contudo as aspas e a referência explícita não constituirão uma necessidade absoluta como proteção contra o plágio se o autor se encontrar inserido num contexto em que a palavra plágio é devidamente entendida. ${ }^{11}$

Um terceiro exemplo: Um estudante apresenta, em versão preliminar, um documento do qual $80 \%$ é cópia direta, sem que no entanto forneça qualquer indicação da fonte nem qualquer sinalização de que houve utilização das palavras de outrem. Tal prática é inaceitável e

\footnotetext{
11 É de uma forma muito deliberada que recorro a este exemplo, porque o Diretor do Office of Independent Adjudicators, no Reino Unido, se referiu a um caso exatamente idêntico; ou seja, em que uma estudante de mestrado copiou 11 palavras de uma determinada fonte sem fazer qualquer menção à respetiva proveniência, com o resultado de que a universidade propôs reprovar-lhe a dissertação por motivo de plágio e recusar-lhe créditos pelo trabalho desenvolvido ao longo de todo o ano letivo (Deech, 2006). A estudante recorreu, desafiando a comunidade académica a rever os procedimentos relativos a penalizações, o que, por sua vez, conduziu ao projeto AmBer, a que adiante farei referência.
} 
merecedora de comentário que o afirme de forma inequívoca ('Isto será plágio se...'), alertando para as consequências caso o autor ou autora não proceda, antes da apresentação final, a alterações em conformidade com aquilo que são os requisitos vigentes com respeito a referenciação bibliográfica. O estudante irá necessitar de orientação específica com vista a compreender e saber interpretar os comportamentos inerentes à aprendizagem construtivista. Todavia, o trabalho, neste estádio, não é plágio, uma vez que ocorreu numa primeira versão; ou seja, ainda não foi submetido para efeito de obtenção de nota ou créditos.

Em resumo, para se determinar a ocorrência ou não ocorrência de plágio há que ter em consideração as indicações presentes no próprio trabalho em apreço, o contexto, e ainda o significado, em termos académicos, de que o ato do estudante se reveste. Determinar a ocorrência de plágio não implica emitir juízos sobre as motivações do estudante ou sobre as razões do seu comportamento. Mas a fixação de penalizações ou de consequências já implica, efetivamente, que se façam juízos quanto à gravidade (indagando, por exemplo, 'Qual o nível de gravidade deste plágio?'). Um dos critérios para aferir a gravidade é a circunstância de o trabalho em causa poder contar - ou não - para a obtenção de créditos. As penalizações e as consequências obrigam ainda à formulação de juízos sobre a intenção, incluindo juízos sobre a ocorrência ou não ocorrência de ludíbrio.

\subsubsection{Definição de ludíbrio}

O ludíbrio é difícil de definir, mas para que um comportamento seja considerado ludíbrio tem de haver algo mais do que a demonstração de que ocorreu uma infração das regras da universidade. Por norma, o ludíbrio implica que aquele que ludibria busque benefício de uma maneira desleal. É evidente que existem formas de ludíbrio 
que não envolvem plágio. Assim, os estudantes que recorrem ao ludíbrio poderão, por exemplo, levar para os exames telefones escondidos, levar as respostas escritas nos braços, conseguir previamente as perguntas de um teste, inventar mentiras sobre doenças de familiares, etc. No contexto do plágio, o ludíbrio implica que haja uma tentativa deliberada de contornar ou evitar o esforço laborioso a que a compreensão e devida sinalização do trabalho de outrem obriga. Aquele ou aquela que ludibria esconde os seus atos, tentando criar no avaliador uma impressão falsa. Quando o estudante ludibria através do recurso ao plágio, está a tentar obter créditos por uma aprendizagem que não fez e benefícios de que não é merecedor.

\subsubsection{Plágio, ou ludíbrio com recurso ao plágio?}

Há casos de plágio que não configuram ludíbrio, e são muitos os autores que defendem a necessidade de destrinçar um do outro. Vejase, por exemplo, Ashworth, Freewood e Macdonald (2003); Partridge e West (2003); Hunt (2004); Blum (2007); Yeo e Chein (2007); Howard (2008); de Lambert, Ellen e Taylor (2006), entre muitos outros. Diversos estudos mostram que o ludíbrio não ocorre senão numa minoria de casos. Um estudo australiano (Martin e Haeringen, 2011), por exemplo, analisou o trajeto dos casos ocorridos no seio de uma universidade ao longo de quatro anos, concluindo que três quartos dos casos de plágio justificavam uma 'resposta educativa'. McGowan (2005) defende com solidez esta ideia no caso de estudantes internacionais que utilizam o inglês como língua adicional. Na minha universidade, onde durante mais de uma década procedemos à gestão planeada e ao registo de muitos milhares de casos, apurámos que em cerca de metade destes se impunha a hipótese de se tratar de infração dos regulamentos académicos por parte do estudante, mas sem tentativa de obtenção de benefício injusto. Por outras palavras, em cerca de metade dos casos 
os estudantes plagiaram mas não ludibriaram. A minha experiência empírica de conversas com centenas de professores a quem, um pouco por todo o mundo, tenho feito perguntas sobre esta questão vai no mesmo sentido (embora alguns - com base numa evidência igualmente empírica e pontual - tenham uma visão acentuadamente diversa, achando que a maioria dos estudantes recorre ao ludíbrio).

Por norma, a ocorrência de plágio sem ludíbrio dá-se devido a uma falta de consciência e/ou de competência e/ou à circunstância de a quantidade de texto ou informação copiada ou não referenciada ser tão reduzida que não tem qualquer reflexo sobre a capacidade do trabalho submetido para demonstrar o saber do estudante. Ou seja, não deixa de ser plágio e não deixa de precisar de ser tratado como tal. Conheço muitas situações em que o plágio não é tratado como plágio - em que o professor porventura se limita a atribuir uma nota baixa ou a dizer aos estudantes para serem mais cuidadosos nos trabalhos, no que respeita à inclusão de referências. Quando tal sucede, o estudante não só não aprende qual o uso correto como acaba por perder a oportunidade de dominar as competências pedagógicas relacionadas com a referenciação (Bretag et al., 2011). Alguns estudos apontam para a ideia de que a tolerância e a opção por não chamar o plágio pelo nome correto poderão acentuar nos estudantes, ao invés de a diminuir, a propensão para o plágio e para cometer infrações ainda mais graves no futuro (Whitely e Keith-Spiegel, 2002; Walker, 2010).

\subsubsection{As complexidades do mal-entendido}

O mal-entendido é algo de complexo. Bretag et al. (2011) fazem notar que o estudante pode compreender o sentido da palavra 'plágio' (se bem que a evidência revele que tal não é o caso, mesmo quando o estudante afirma ter compreendido) sem que, no entanto, consiga aplicar esse conhecimento na prática. 
O mal-entendido processual (quer dizer, a ignorância sobre 'como' funciona o plágio) ocorre, frequentemente,

- quando o estudante muda de área disciplinar, defrontando-se com novas expectativas;

- quando o estudante esteve algum tempo afastado do ensino superior, visto que as normas respeitantes à referenciação bibliográfica se tornaram bem mais apertadas nesta última década;

- quando existem diferenças significativas entre as normas atuais e as precedentes no que à elaboração de trabalhos individuais diz respeito. Tal pode ocorrer no caso de estudantes oriundos de setores com uma prática profissional própria, com estudos feitos noutros países, e/ou provenientes de escalões inferiores de ensino. Neville (2009) documentou esta situação quando interrogou estudantes de pós-graduação estrangeiros a propósito da sua experiência de adaptação às práticas de referenciação bibliográfica em vigor no Reino Unido, tendo apurado que $25 \%$ dos 255 estudantes inquiridos declararam que não sentiram quaisquer dificuldades quanto ao plágio no decurso dos respetivos estudos, uma vez que as expectativas com que depararam no Reino Unido eram as mesmas que havia 'nas suas terras'. Outros $25 \%$ afirmaram não ter sido problema a mudança para as expectativas encontradas no Reino Unido, e $50 \%$ referiram ter passado por 'uma transição radical ao nível educativo e social' (p.1). Metade dos inquiridos disse-se confusa e "profundamente preocupada com as questões de plágio' mesmo após vários meses de ensino intensivo. É raro os estudantes terem a noção de que se vão confrontar com uma mudança dos requisitos quando transitam de um dado quadro de práticas pedagógicas para outro, geralmente num país diferente (Gu, Schweisfurth e Day, 2012); 
- quando o estudante, ao matricular-se, traz consigo pouca ou nenhuma experiência de escrita autónoma, de busca e utilização das fontes, ou de passar as suas ideias a escrito de uma maneira clara (Davis, 2013). Na bibliografia sobre o ensino de estudantes de mobilidade é comum observar estudantes surpresos ou mesmo chocados com as novas exigências com que se confrontam (Carroll, no prelo);

- quando o estudante participa num programa em que não esperava ter de escrever. Há professores de arquitetura, matemática, engenharia e belas-artes (entre outros) que falam do choque de estudantes seus ao descobrirem que, para além dos conhecimentos e competências na própria disciplina, têm de dominar a escrita académica.

Não sendo exaustiva, a lista justifica que se parta do princípio pragmático de que, independentemente da sua prévia experiência ou formação, todo o estudante precisa que lhe ensinem as suas responsabilidades quanto à utilização e sinalização do trabalho alheio. Ensinar competências é mais eficaz do que acenar com ameaças por motivo de ludíbrio (Sutherland-Smith, 2010).

\subsubsection{Os estudantes que não seguem as normas depois de compreendidas}

A própria transição para novos patamares de compreensão e de competência remete para a necessidade de um sistema que, sendo flexível e baseado em juízos formulados caso a caso, não deixe de ser coerente. Tal implica que haja um sistema de penalizações e que estas sejam ajustadas à gravidade das infrações, incluindo as mais ligeiras. Quanto às consequências, poderão assumir a modalidade de uma conversa com o docente, destinada a reforçar os requisitos 
pedagógicos, e devidamente gravada por forma a impedir que o estudante possa vir, posteriormente, a fazer-se de inocente. Poderá ser também a obrigatoriedade, para o estudante, de se submeter a um acompanhamento tutorial online. Nalguns casos a penalização poderá ser a correção e reapresentação do trabalho (embora muitas vezes esta medida signifique uma penalização principalmente para o professor e tenda a não ser sustentável).

A destrinça entre plágio e ludíbrio, aliada ao reconhecimento de que o plágio pode ocorrer com níveis diversos de gravidade, significa que irão, forçosamente, colocar-se casos graves de irregularidades no que respeita à conduta académica.

\subsubsection{Identificação dos casos de infração grave}

Para que um caso seja considerado uma infração académica grave, o decisor terá de dar por provado que o estudante conhece as normas e convenções da referenciação bibliográfica; que possui competência bastante para as respeitar; e que existe fundamento para se concluir que procurou deliberadamente contornar o esforço laborioso a que o respeito pelas normas obriga. Entre os exemplos de infração grave estará o caso daquele estudante que, embora conhecedor das normas relativas à utilização da citação literal, recorra à cópia sem fornecer a mínima indicação de que o texto constitui uma apropriação ipsis verbis das palavras de outrem. A infração grave assume contornos mais acentuados quando o texto copiado constitui uma porção significativa do todo que suporta a pretensão, por parte do estudante, à obtenção de créditos. A infração torna-se ainda mais grave quando o estudante procura deliberadamente fazer com que o material de que se apropriou pareça seu ou quando procura deliberadamente gerar no avaliador uma impressão falsa quanto à efetiva autoria do trabalho apresentado. Ou seja, o estudante poderá, por exemplo, retirar da 
web uma quantidade significativa de texto acerca do [tema $\mathrm{x}$ ] e usar a função 'buscar e substituir' para trocar todas as referências ao [tema x] por referências ao [tema y]. [Adiante abordar-se-á a questão de saber o que é que os termos 'porção significativa' e 'grave' poderão querer dizer em situações concretas].

Outros exemplos de atos considerados infração grave acontecem quando o estudante:

- altera uma obra ou um texto por forma a dar a ideia de que o estudante realizou uma quantidade de trabalho maior do que aquela que produziu na realidade - por exemplo acrescentando a um trabalho escrito uma lista bibliográfica descarregada algures, mas que de facto não consultou, e inserindo de seguida pretensas referências pelo meio do texto;

- volta a submeter um trabalho a que já foi atribuída nota;

- utiliza programas de tradução para alterar um texto, fazendo assim com que este 'escape ao radar' das ferramentas de cotejo textual;

- submete trabalho feito por um colega.

A infração académica grave é o atropelo a normas consideradas importantes num contexto de aprendizagem mas que poderão ou não ter idêntico significado fora dos muros da universidade. Por outro lado, todos estes exemplos configuram também casos de ludíbrio, uma vez que neles se busca obter benefício injusto [em termos de aprendizagem].

Não é fácil dizer com que frequência os casos de plágio configuram, simultaneamente, exempos de infração grave e/ou ludíbrio. Quem se quiser abalançar a medir os níveis de ocorrência entre os seus próprios estudantes terá de interpretar com cautela resultados do tipo ' $80 \%$ dos estudantes afirmam recorrer ao ludíbrio'. Uma resposta destas deixa por especificar o grau de frequência e os contextos em que 
os casos ocorrem, o peso relativo da porção do trabalho em causa, qual o impacto efetivo sobre o percurso académico do estudante, etc. A ausência de informação que seja fiável, comparável e relevante torna difícil responder a uma pergunta tão genérica como 'até que ponto deveremos preocupar-nos com a infração grave?', uma vez que toda a resposta será mera 'especulação baseada no ouvir dizer' (Scanlon apud Walker, 2010: 42). Passando em revista a ampla evidência disponível, Walker (2010) descarta os testemunhos autoparticipados, que considera problemáticos, improváveis e 'de validade reduzida' (p. 42). Ainda menos fiável é pedir aos estudantes que quantifiquem o grau de ocorrência. Um estudo regista que $8 \%$ dos estudantes inquiridos afirmaram que copiavam de fontes digitais sem indicar a proveniência, mas sugerindo, ao mesmo tempo, que mais de $50 \%$ dos colegas o faziam (Scanlon e Neuman apud Walker, 2010). Existe, no entanto, alguma investigação de pequena escala, no âmbito de estudos locais, capaz de nos fornecer respostas mais localizadas e também de menor escala. Walker levou a cabo um projeto de investigação de cinco anos sobre a prática efetiva dos seus estudantes com respeito à cópia sem referenciação bibliográfica. Utilizando programas de cotejo textual, este autor dividiu os trabalhos escritos em 'plágio moderado' (menos de 20\% de texto copiado sem atribuição da autoria) e 'plágio extenso' (casos de $20 \%$ ou mais do trabalho a ser objeto de cópia não sinalizada). Walker situa em pouco mais de um quarto (26\%) o número de trabalhos escritos considerados cópia moderada ou extensa, embora não concretize até que ponto vai essa extensão. Ainda no âmbito do mesmo estudo, este autor concluiu que, em 566 trabalhos entregues, 5 eram, 'em grande parte ou na totalidade, obra de outro estudante', e que 'numa outra tarefa dada ao mesmo grupo de estudantes, foram 6 em 532 os casos de "apropriação" registados'. Walker, que não detetou casos de trabalhos encomendados, observa ainda que não se pode generalizar a partir destes resultados, apurados na Nova Zelândia a partir de uma coorte de estudantes (um misto de nacionais e estrangeiros) de uma licenciatura em economia e gestão. 
Estudos há, também, de maior escala. Nos EUA, Donald McCabe tem levado a efeito inquéritos envolvendo centenas de milhar de estudantes, com base em relatos de auto-observação das práticas de cópia e outras formas de utilização de texto digital sem referenciação. Segundo McCabe, em 1999, 13\% dos estudantes afirmaram copiar com regularidade (sem, contudo, especificar que porção dos trabalhos apresentados tinha essa origem), sendo a percentagem de $41 \%$ em 2001. Tais resultados revelam a subida acentuada do índice de ocorrência a partir do momento em que os recursos da Internet passaram a estar mais disponíveis. No entanto, o estudo nada diz sobre a extensão ou volume da cópia (McCabe, 2003). Num estudo realizado em 2005, McCabe pediu a estudantes que indicassem quatro comportamentos considerados 'batota' ou ludíbrio grave. A lista daí resultante dá nota das respostas de estudantes de licenciatura (Lic) e de pós-graduação (PG) que revelaram ter tido estes comportamentos no ano anterior:

- 'apresentação de trabalho da autoria de outrem' - 8\% Lic / 4\% PG;

- 'cópia de grandes porções de texto escrito sem indicação da fonte' - 7\% Lic / 4\% PG;

- 'apresentação de trabalho feito por outro [estudante]' - 7\% Lic / 3\% PG;

- 'obtenção de trabalho através de uma "fábrica de ensaios para exames»' - 3\% Lic / 2\% PG.

McCabe acrescenta que 'é talvez de presumir que o nível efetivo seja mais elevado do que mostram estes resultados' (McCabe, 2005).

Na minha universidade, no Reino Unido, o conjunto das infrações aos regulamentos académicos foi classificado de acordo com três níveis, o mais gravoso dos quais recebeu a designação de falta ou 
infração grave ${ }^{12}$. Aqui, os registos coligidos ao cabo de mais de uma década mostram que as situações de infração grave se situaram, habitualmente, entre $10 \%$ e $20 \%$ do número total de casos. Desses casos, por sua vez, foi diminuto o número dos que envolveram fraude e/ou infração às normas punível com aplicação de multa, expulsão, ou recusa da outorga de habilitação profissional. Com efeito, esse número raramente atingiu os dois dígitos, entre mais de 20.000 estudantes matriculados (ver Carroll e Appleton, 2005; Carroll, 2005). Por outro lado, não há maneira de saber até que ponto estes resultados representam uma subavaliação do número de casos realmente verificados.

Voltando à questão da frequência e do nível de gravidade das infrações de natureza académica, proponho que a melhor forma de solucionar o dilema é partir do princípio de que a infração grave ocorre num número de casos significativo - suficientemente significativo para se pressupor que se trata do método preferencial de alguns estudantes na maior parte das coortes. Sempre que se verificam índices de infração baixos ou muito baixos, o mais certo é haver omissão de casos ou estes estarem a passar despercebidos. Por fim, independentemente do nível, as indicações de que dispomos já são de molde a justificar que se invistam recursos e esforços na gestão da totalidade dos casos, mas não a justificar a crença de que todos os casos configuram infração grave nem que devamos criar sistemas especificamente vocacionados para a deteção e gestão desse nível de infração. É minha experiência que a criação de sistemas primacialmente orientados para a gestão do ludíbrio leva a que os processos se tornem sobrejuridificados e burocratizados; a que as relações azedem, devido à atitude defensiva e ao ambiente de suspeição; e a que sejam adotadas medidas que ameaçam a totalidade dos estudantes

12 A divisão da classificação em três níveis é comum a muitos sistemas de gestão. Veja-se, por exemplo, Yeo e Chen (2007) e a sua descrição do procedimento em vigor na Curtin University, na Austrália, onde é utilizada uma ficha de uma só página. 
no processo de aprendizagem - tudo isso quando a verdade é que nada indica que exista melhor forma de gestão dos casos do que uma abordagem de tipo construtivo e centrada na aprendizagem. Para visões consonantes com esta, veja-se, por exemplo, Sutherland-Smith (2010); Blum (2007); Devlin (2006).

\subsubsection{Distinção entre ludíbrio e fraude}

O estudante que comete fraude é levado pelo desígnio de enganar. E quando o faz, ele está, em alguns casos, a infringir não só as normas próprias do meio universitário, como também as leis reconhecidas fora desse meio. Nos exemplos de comportamento fraudulento incluem-se a falsificação de dados, o roubo, a obtenção de dados através de ameaça ou intimidação, o fazer-se passar por outrem e/ou pagar a outrem para produzir trabalho que depois é apresentado como sendo de quem o apresenta, tudo isso para obtenção de créditos ou outro benefício próprio. Este último exemplo, frequentemente designado por encomenda e, por vezes, ludíbrio contratado (Lancaster e Clark, 2007), é também muitas vezes gerido em função das normas criadas para a gestão do plágio. A prática de lidar com o trabalho encomendado como se de plágio se tratasse deve-se, muito provavelmente, à circunstância de os produtos encomendados serem submetidos dentro do contexto letivo, assemelhando-se por isso aos trabalhos gerados pelas modalidades de infração académica grave em que se inclui o plágio. A verdade, no entanto, é que o trabalho encomendado sai, em rigor, fora do quadro das políticas de gestão do plágio. Assim, nestas deverão estar previstas maneiras de separar liminarmente os casos de encomenda, que haverá então que tratar como qualquer outra prática fraudulenta. Adiante avançam-se mais recomendações acerca da gestão da fraude.

Concluindo, uma política e um conjunto de procedimentos eficazes com vista à gestão do plágio estudantil passam, obrigatoriamente, 
por um entendimento comum e devidamente fundamentado daquilo que são as diferenças entre plágio, ludíbrio e fraude. As políticas a concretizar deverão estabelecer de maneira explícita a correlação entre, por um lado, os valores relativos à aprendizagem estudantil e, por outro, os requisitos pedagógicos respeitantes à utilização e sinalização do trabalho alheio. Elas deverão, assim, explicitar devidamente o modo como os estudantes têm de fazer prova da sua aprendizagem, bem como o modo como devem sinalizar o trabalho alheio. Há que ter o cuidado de evitar dar a ideia de que as convenções da referenciação bibliográfica são universalmente reconhecidas como uma evidência de integridade. Pelo contrário, as convenções e requisitos do foro pedagógico andam intimamente ligados àquilo que é o comportamento considerado importante num meio universitário/ de investigação específico. Já no caso do ludíbrio e da fraude, porém, são convocados os valores universais da justiça, da honestidade e da transparência.

Passo, de seguida, a ocupar-me daquilo que serão as caraterísticas de uma política institucional e os procedimentos para uma gestão justa, coerente, defensável e eficiente do plágio estudantil.

\subsection{Guia de boas práticas das políticas e procedimentos a seguir na gestão do plágio estudantil}

Para efeitos do presente capítulo, os exemplos de diretrizes e de boas práticas apontados restringem-se a autores e projetos sediados em universidades de língua inglesa. Seguramente existem outros exemplos para além da bibliografia com que estou mais familiarizada. Da lista de bibliografia fornecida no final constam as referências completas das fontes a que tive acesso. Entre as fontes anglófonas especialmente úteis para o estudo de boas práticas, contam-se as seguintes: 
- Policy Works.

Relatório publicado em 2011 pela Higher Education Academy ${ }^{13}$ do Reino Unido. Propõe um elenco de 12 aspetos para uma abordagem eficaz da gestão do plágio;

http://www.heacademy.ac.uk/assets/documents/academicintegrity/policy_works.pdf

- Bretag et al. (2011), 'Core elements of exemplary academic integrity policy in Australian higher education'.

Artigo australiano assinado por nove autores, em que se resumem os resultados de um estudo de três anos, financiado pelo Estado, sobre políticas e procedimentos destinados a estimular e apoiar a integridade académica. Os resultados baseiam-se nas respostas de mais de 15.000 estudantes a um questionário sobre as respetivas atitudes e crenças;

- Sutherland-Smith (2010), 'Retribution, deterrence and reform: the dilemmas of plagiarism'.

Artigo de uma professora universitária australiana com formação em direito, em que esta analisa o impacto que a linguagem jurídica e as metáforas da esfera do crime têm sobre a conceção e execução das estratégias para a gestão do plágio. A autora faz uma descrição das reações a situações de perceção de pânico moral, afastando qualquer receio de que o plágio seja algo de incontrolável.

- 'Defining and Avoiding Plagiarism: The WPA Statement on Best Practices'.

Documento disponibilizado no sítio eletrónico do Conselho dos Writing Program Administrators ${ }^{14}$ - WPA (2003), sediado nos EUA. Na descrição que dele é dada, lê-se que

'Academia do Ensino Superior'. [N.T.]

14 Administradores de Programas de Composição Escrita. [N.T.] 
procura 'dar resposta, em quatro vertentes, às crescentes preocupações com o plágio: definindo o que é o plágio; apontando algumas das causas do plágio; propondo um conjunto de responsabilidades (tanto de discentes como de docentes e responsáveis administrativos) para fazer frente ao problema do plágio; e recomendando um conjunto de práticas de ensino e aprendizagem passíveis de reduzir significativamente a probabilidade de ocorrência do plágio';

http://wpacouncil.org/positions/WPAo plágio.pdf.

- (Carroll, 2007) 'The Handbook for Deterring Plagiarism in Higher Education'

Nesta obra detenho-me sobre medidas e procedimentos, entendidos como parte integrante de uma abordagem holística ou concertada do problema da gestão do plágio.

Muitas universidades desenvolveram políticas que posteriormente foram revendo à luz da experiência, publicando, nalguns casos, os resultados obtidos. Veja-se, por exemplo, Park (2004) e Macdonald e Carroll (2006), no Reino Unido; Devlin (2006), Yeo e Chein (2007) e Martin e Haeringen (2011), na Austrália; de Lambert, Ellen e Taylor (2006), na Nova Zelândia.

\subsection{Caraterísticas de uma política eficaz de gestão do plágio}

\subsubsection{A gestão do plágio requer uma abordagem de tipo bolístico}

As ações a empreender, bem como as responsabilidades, devem ser partilhadas por estudantes, professores, e pela universidade no seu todo. A gestão do plágio estudantil deve, assim, procurar articular as iniciativas de maneira a: 
- passar para os estudantes a informação pertinente.

As políticas e procedimentos deverão dizer explicitamente de que modo os estudantes devem tomar conhecimento dos regulamentos e requisitos pedagógicos respeitantes à utilização e sinalização do trabalho alheio, não se ficando, assim, pela mera mecânica e pelas convenções de formatação de um dado sistema de referenciação bibliográfica;

- fomentar o desenvolvimento das competências dos estudantes. Segundo um estudo realizado na Austrália, os estudantes 'não têm falta de informação sobre a integridade académica; o que se passa é, antes, que não recorrem à vasta informação disponível' (Gullifer e Tyson apud Bretag et al., 2014: 1165). O planeamento deverá fomentar um desenvolvimento ao longo do tempo, visando uma evolução progressiva das competências neste domínio;

- assegurar que a avaliação visa promover o trabalho genuíno, desincentivando assim, por outro lado, a possibilidade de trabalho passivel de ser copiado, 'pesquisado' ou falseado.

- criar procedimentos de gestão que não prejudiquem o avaliador que deteta o plágio.

A deteção de um determinado caso não deverá 'sair cara' a quem o aponta. As modalidades de prejuízo pessoal podem traduzir-se em termos de tempo, mau relacionamento com os colegas docentes, riscos para o relacionamento com os estudantes, receio de ser contrariado ou posto em dúvida, etc. Tenho ouvido a literalmente centenas de professores, em universidades de todo o mundo, a confirmação da ideia de que, sempre que a deteção de um caso implica estas desvantagens, acabam por evitar apontá-los. McCabe (2005) refere que $41 \%$ dos professores que responderam aos seus amplos inquéritos afirmaram ignorar casos de plágio. Martin e Haerignen (2011), por seu turno, registam um aumento 
de oito vezes na comunicação de ocorrências após a introdução de um sistema em que essa comunicação passa a ser centralmente apoiada e a contar com mecanismos de participação formal claros. Outro modelo passível de poupar a figura do 'detetor' é o sistema do Academic Conduct Officer, abaixo descrito.

- apostar numa gestão coerente.

A coerência faz aumentar a probabilidade de que os procedimentos sejam vistos como justos e merecedores de confiança. Para que a coerência esteja devidamente alicerçada, as políticas adotadas deverão explicitar de que forma, por quem, e com que base em que critérios é que as decisões são tomadas. Além disso, nos procedimentos deverá estar prevista a forma como os decisores comunicam entre si, como comparam as decisões, partilham as dúvidas, etc. Os benefícios advindos da criação de toda uma comunidade em torno de uma prática constituem uma das razões pelas quais se recorre a especialistas - e não, de forma isolada, a membros do corpo docente - para emitir decisões do foro académico, porquanto é maior a probabilidade de os especialistas irem sedimentando a experiência acumulada após um número significativo de casos. Acresce que os especialistas são também de mais fácil acesso para efeito de acompanhamento e de desenvolvimento profissional (Carroll e Appleton, 2005). Tudo isto são fatores que reforçam a coerência;

- manter registos.

As políticas adotadas devem dizer explicitamente que dados devem ser guardados, de que forma e por quem;

- tornar clara a articulação com os procedimentos relativos à garantia da qualidade.

A articulação com a qualidade codifica as responsabilidades pela gestão do plágio estudantil ao mesmo tempo que 
mantém os problemas na agenda das instituições e reforça a probabilidade de aumento dos recursos a afetar.

\subsection{A gestão do plágio requer que as decisões do foro pedagógico pertençam aos docentes}

Há países em que as decisões respeitantes ao plágio cabem ao corpo docente; noutros, elas ficam fora da alçada das medidas normais em vigor no âmbito da qualidade pedagógica. Quando é esta última situação que vigora, a gestão das ocorrências torna-se bastante problemática.

O trabalho desenvolvido por Glendinning e colegas (2013) no âmbito de um estudo sobre a gestão do plágio realizado em toda a União Europeia concluiu que em muitos países se exige que o processo de decisão seja partilhado entre responsáveis académicos e outras entidades, como advogados, provedores, e defensores da causa dos estudantes. Sempre que o processo de decisão sofre alteração, tal significa, por norma, a passagem de uma ênfase na aprendizagem para uma ênfase nas responsabilidades e nos direitos legais (Carroll e Zetterling, 2009). Entre as consequências de uma eventual passagem para procedimentos de pendor legalista e com níveis de prova contam-se as seguintes:

- maior demora dos processos.

Em lugares em que trabalhei e onde a responsabilidade estava cometida a Academic Conduct Officers, por exemplo, os casos eram tratados no prazo de uma ou duas semanas; na universidade sueca em que também servi e onde a gestão das ocorrências não se encontrava sob o controlo dos docentes, a duração média de cada processo era de 11 meses;

- aumento da exigência em matéria de prova, geralmente indo muito para além do que seria um juízo com base na ponderação das probabilidades. O critério da ponderação das 
probabilidades constitui o nível normal no âmbito do direito civil, porém aqui assiste-se à introdução de um requisito de prova 'para além da dúvida', o que é completamente descabido em contexto pedagógico (Sutherland-Smith, 2010);

- aumento dos níveis de confrontação.

Sucede muitas vezes tornarem-se comuns os interrogatórios e inquirições a docentes - colocando-os na defensiva -, a contestação das decisões do foro pedagógico, etc. A título de exemplo refira-se que, antes da criação dos ACOs e da fixação de níveis de prova necessária para a produção da respetiva decisão, a documentação de uma ocorrência numa universidade do Reino Unido obrigava, em média, a 12 dias de trabalho. Após a reestruturação dos sistemas no sentido de garantir que os juízos tivessem fundamento em determinados critérios e fossem cometidos a especialistas do gabinete do ACO, o processo de averiguação e confirmação de cada caso passou a poder ser concluído, em regra, no espaço da reunião/entrevista de uma hora ou, nos casos complicados, em algumas horas apenas. Em contraste com esta situação, na Suécia os casos eram discutidos na presença de advogados e de um juiz aposentado e implicavam resmas de documentos, por vezes com mais de $10 \mathrm{cms}$;

- redução do número de processos geridos.

Não obstante a minha universidade inglesa e a minha universidade sueca terem, aproximadamente, a mesma dimensão e serem frequentadas por estudantes com perfil idêntico, os casos identificados no Reino Unido em que o plágio foi expressamente gerido e registado ascenderam a muitas centenas por ano, ao passo que na universidade sueca não passaram de poucas dezenas, havendo mesmo um ano sem qualquer ocorrência;

- inflexibilidade das decisões.

A manutenção dos processos na esfera propriamente académico-pedagógica permite a utilização de tabelas de 
penalização (abaixo descritas), que poderão variar de maneira a refletir os níveis de gravidade. Quando a gestão é feita fora desse contexto, as penalizações tendem a ser em número reduzido, não deixando, por vezes, ir além da suspensão por um período determinado. Esta circunstância pode levar a que tanto professores como estudantes sintam que as penalizações são injustas e/ou desproporcionadas.

\subsection{A gestão do plágio requer uma utilização hábil das estratégias de deteção}

Os docentes e, em geral, os corretores ou avaliadores de testes deverão lançar mão de um vasto leque de mecanismos para identificar material não original apresentado pelos estudantes. Walker (2010) observa que a competência na deteção '... tem a ver com experiência, perspicácia, domínio dos conteúdos, um bom conhecimento da turma, e bom senso' (p. 43). Constituirá má prática identificar o plágio, seja de tipo eletrónico ou outro, com base em apenas uma destas condições, tal como não será realista supor que os professores possuem, à partida, a perspicácia e as competências necessárias a um uso eficaz da metodologia usada, qualquer que ela seja (Badge, Cann e Scott, 2007). As políticas a adotar terão de acautelar a forma de prover as necessidades de desenvolvimento profissional dos professores enquanto agentes de deteção do plágio.

\subsubsection{A gestão dos casos detetados tem de ser eficiente}

Nas instituições em que os casos de plágio são geridos de maneira eficaz, a sua ocorrência é relativamente elevada. Quando o número é pequeno, é muito provável que tal se deva mais a uma 
gestão deficiente do que a um índice baixo de frequência. Daí dever concluir-se que há que conceber procedimentos no sentido de tratar os casos de plágio como um aspeto normal e de dimensão considerável da vida académica. Para serem eficientes, os procedimentos têm de ser sustentáveis e dotados dos recursos adequados, inclusivamente assegurando que as exigências em matéria de prazos têm correspondência no planeamento da carga de trabalho a distribuir e na nomeação de quem irá ser chamado a investir o seu tempo na gestão dos processos.

\subsubsection{Os procedimentos de gestão dos processos têm de ser justos, coerentes e defensáveis}

A coerência é passível de ser posta em risco em qualquer momento da abordagem holística. Assim, a incoerência poderá residir no próprio ensino ministrado, nas oportunidades de exercitar as competências, na irregularidade do contacto com formas de avaliação bem concebidas, na inconstância da disponibilidade ou abertura para a identificação de casos, etc. E no entanto parece existir, da parte tanto de estudantes como de professores, uma particular preocupação no sentido de que haja coerência nas penalizações e na sua aplicação. Com este fim em vista, Tennant e Duggan (2008) e Tennant e Rowell (2009-10) publicaram relatórios no âmbito do projeto AmBer em que se indagava que penalizações eram utilizadas, e com que frequência, nas universidades do Reino Unido, e ainda quais as penalizações preferenciais. Carroll e Appleton (2005) descrevem a utilização de uma tabela de penalizações destinada a garantir a coerência das decisões.

O requisito da defensabilidade obriga a que a informação relativa ao modo como as decisões são tomadas e ao respetivo fundamento seja explícita e transparente. 


\subsubsection{A gestão do plágio estudantil requer um arquivo de re- gistos de qualidade}

A manutenção de registos, e sobretudo a respetiva verificação e avaliação, permitem que tanto as pessoas individualmente como as instituições possam aprender com a gestão que fazem do plágio estudantil e aperfeiçoá-la. Com efeito, o registo de casos poderá levar segmentos da universidade em que não tenha sido evidenciada qualquer atividade neste âmbito a enveredar por medidas eficazes e de tipo holístico.

3.6.4. A gestão do plágio deve enquadrar-se nos procedimentos de gestão da qualidade (GQ) em vigor na universidade

Tanto os dados como as questões de gestão propriamente dita resultantes da deteção e gestão do plágio deverão articular-se com os procedimentos de gestão da qualidade seguidos na instituição. A participação formal poderá ser feita junto de comissões específicas, de pessoas, ou de estruturas de governo interno.

\subsection{A adoção de uma abordagem holística: por onde começar?}

Ao fim de mais de uma década a trabalhar com centenas de universidades no desenvolvimento e montagem de políticas para lidar com o plágio, aprendi que é possível começar em qualquer ponto da lista holística de atividades acima referida. Algumas universidades começam pela informação aos estudantes, outras começam por reelaborar as políticas em vigor, outras por rever os métodos de avaliação, e outras ainda começam por incentivar a deteção de casos e dotá-la de recursos, normalmente através da introdução de 
software de cotejo textual. A maioria das universidades parece evoluir posteriormente para outras questões constantes da lista e por vezes acaba por aplicá-las na totalidade, completando assim a abordagem holística. Geralmente esse processo leva anos.

Não obstante as universidades poderem começar em qualquer ponto, há um elemento da abordagem holística que parece especialmente apto a desbloquear a letargia e resistência institucionais. Esse elemento é a garantia, para quem deteta um caso, de que não irá, por isso, sofrer prejuízo pessoal significativo. A partir do momento em que deixam de se sentir ameaçados, pressionados, inseguros e pouco à vontade com o facto de terem de lidar com casos de plágio, os professores ficam muito mais disponíveis para se envolverem com as medidas e os procedimentos relacionados com a sua gestão. A partir do momento em que veem que o sistema é flexível sem deixar de ser capaz de gerar penalizações coerentes e adequadas, começam a confiar nele e, consequentemente, a utilizá-lo. A partir do momento em que discentes e docentes veem que os resultados são justos, é habitual assistir-se a uma subida do número de participações formais de ocorrências de todo o tipo, e com o passar do tempo fica provado que a boa gestão gera um efeito positivo no comportamento dos estudantes. O número de casos acaba, assim, por baixar (Walker, 2010; Martin e Haeringen, 2011).

Um dos mecanismos para atingir resultados positivos consiste em criar um sistema em que um pequeno número de especialistas - os 'Academic Conduct Officers' - faz a gestão dos casos de plágio, de infração grave e de ludíbrio; do cargo faz parte também a atribuição de penalizações. De acordo com este sistema, os casos de fraude têm de ser remetidos pelos ACOs para comissões disciplinares da universidade. De seguida descreve-se o modo como o sistema ACO está concebido e como, ao cabo de mais uma década de experiência, ele deu provas de resultar na prática. 


\subsection{Linhas gerais do sistema do Academic Conduct Officer}

Dito resumidamente, o sistema ACO fixa o modo como aquele ou aquela que avalia um trabalho escrito deve identificar os casos de plágio e passá-los para as mãos dos especialistas. Os ACOs averiguam os casos, confirmando-os ou indeferindo-os, atribuem a penalização respetiva, registam a decisão tomada, e asseguram que o trabalho do estudante reentra no processo de avaliação normal, de maneira a que a penalização possa ser aplicada. A presente descrição contempla apenas alguns elementos de todo este quadro. Para uma descrição mais completa, ver Carroll (2007).

O primeiro passo cabe a cada professor e consiste em decidir se um determinado caso necessita de ser remetido ao ACO ao verificar-se que reúne todos os critérios da definição acima referida (Fishman, 2009). Se tal não suceder mas se o trabalho continuar a ser insatisfatório, ele poderá ser gerido através do processo normal de avaliação. Assim, e por exemplo, se o estudante usou de forma deficiente as convenções da referenciação bibliográfica mas indicou a fonte de uma maneira informal, o respetivo avaliador poderá tratar pessoalmente do problema. E quando a parte não genuína constitui uma porção diminuta do trabalho (algumas frases apenas, por exemplo, ou 5\% do todo, em passos não fundamentais), aí o plágio não interfere na capacidade do avaliador para julgar o trabalho pelos conhecimentos nele demonstrados, e o caso pode ser gerido pelo professor. A coerência passa muito pelo treino dos professores/avaliadores de modo a saberem fazer estas distinções.

Os ACOs são nomeados pela respetiva escola ou departamento para tratarem de ocorrências 'locais'. O seu âmbito de ação é variável, podendo, nalguns casos, abranger a totalidade da instituição. Há situações em que o cargo é assumido por funcionários administrativos mais antigos, mas por norma o responsável pelo departamento ou o Diretor nomeia um dos docentes com maior antiguidade (ou vários, 
como sucede nas unidades de maior dimensão e com um grande número de estudantes). O ACO deve ser visto como alguém que está próximo das exigências e preocupações da disciplina e para elas sensibilizado, deve ter a confiança dos colegas, e não lhe devem faltar os recursos que o cargo requer. Precisa de tempo, de oportunidades de desenvolvimento profissional, e de perspetivas quanto a reconhecimento profissional e promoção. A minha universidade acabou por optar pela atribuição, ao ACO, de 2.5 horas vezes o número de casos detetados no ano anterior na unidade de responsabilidade em causa (escola, departamento, secção, etc.). Sendo o número de casos muito variável quanto ao local da ocorrência, o número de ACOs por unidade foi também muito variado. O objetivo foi garantir que as cargas do trabalho distribuído se mantivessem dentro de limites geríveis, bem como assegurar um nível de capacidade suficiente para dar resposta a picos de procura nas épocas de avaliação.

Ao receber um processo, o ACO fica com a responsabilidade da respetiva averiguação (umas vezes conjuntamente com outros, de outras vezes sozinho) e de comunicar com o estudante. Não cabe no presente resumo falar das complexidades da averiguação e dessa comunicação, no entanto há que referir que o modo como devem decorrer e como lidar com o estudante não depende do ACO, mas é sim devidamente especificado e monitorizado, obrigando ao envio e devolução, dentro de prazos predeterminados, de documentos-modelo. Os prazos para reuniões e divulgação de resultados são importantes.

Em cada processo há, obrigatoriamente, lugar a uma reunião/ entrevista com a presença do estudante, do ACO e, eventualmente, de terceiros; as reuniões duram, geralmente, cerca de uma hora. O estudante poderá fazer-se acompanhar de alguém, cujo papel de apoio, no entanto, está previsto que seja bastante limitado. O ACO inicia a reunião tentando indagar se existe fundamento para se concluir que houve infração dos regulamentos académicos e, sendo essa a 
situação, qual o nível de gravidade. Haverá um momento (geralmente cerca de 20 minutos após o início da reunião) em que o ACO decide, ou avançar, por considerar que efetivamente houve uma infração, ou devolver o processo ao docente para nova correção, já no quadro dos critérios normais da avaliação. Nessa altura a reunião é interrompida e é dado ao estudante um breve período de tempo para pensar e decidir se pretende que a reunião prossiga de imediato ou em data posterior. Caso a reunião continue de seguida, o ACO toma a sua decisão quanto ao nível de gravidade. Ao ajuizar sobre o nível de gravidade, os ACOs deverão ponderar os seguintes critérios:

- a porção do trabalho que não é da autoria do aluno.

- a importância relativa dessa parte no conjunto do trabalho. Um ACO poderá assim, por exemplo, ver se o material não genuíno se encontra num apêndice ou no corpo do trabalho; se algum desse material não genuíno chega a comprometer a autenticidade e integridade de determinado aspeto do trabalho - se, por exemplo, torna inválida a argumentação; se essa componente não genuína surge em pontos do texto em que seja tão importante a utilização de material original; etc.;

- o estádio em que o estudante se encontra no seu percurso académico.

Há que ter cautelas especiais nos primeiros tempos/meses após a matrícula. Idênticas cautelas se tornam necessárias quando se tem de levar em conta o estádio da evolução de estudantes que hajam chegado no âmbito de programas complementares ou que tenham ingressado em pós-graduações vindos de instituições com práticas e convenções pedagógicas muito diferentes;

- a circunstância de ter ou não sido concedido ao estudante suficiente ensejo para entender e aplicar as normas relativas à utilização das fontes. 
Provas de que houve 'suficiente ensejo' poderão ser a frequência de um curso de competências de estudo; a presença comprovada numa sessão de orientação oferecida pelo departamento, com posterior acompanhamento - devidamente documentado - em trabalhos entretanto apresentados; demonstração de utilização correta no resto do trabalho escrito em apreço, etc. O juízo sobre se o estudante dispôs ou não de suficiente ensejo para compreender e desenvolver as competências adequadas serve, habitualmente, de suporte indireto para as decisões respeitantes à presença de intenção. Trata-se, em ambos os casos, de juízos de natureza académica, mas na prática afigura-se mais fácil ajuizar sobre níveis de compreensão do que sobre as motivações e intentos do aluno;

- a eventual existência de provas de ludíbrio, entendido como a tentativa deliberada de enganar ou de colher benefício de forma injusta.

O ludíbrio é tratado como uma agravante da infração grave.

A utilização destes critérios tornou-se relativamente simples depois de aplicados em uma dúzia de casos aproximadamente. Não tardou, assim, que os ACOs se movessem à vontade no interior de um sistema que se revelaria suficientemente flexível para lidar com casos extremamente diferentes entre si, se bem que sujeito a um apertado leque de opções (quer dizer, a uma escolha entre não mais que três níveis de gravidade). Perante casos cuja gravidade se lhe afigurasse merecedora de penalização superior ao previsto pelo sistema, o ACO reencaminhava-os para outra instância, a Comissão Disciplinar da Universidade. Tal reencaminhamento foi o resultado habitualmente verificado nos casos de fraude (incluindo os de trabalhos encomendados), de infração grave recorrente, e de infração grave em trabalhos de valor e estatuto elevados, como teses de doutoramento ou 
trabalhos de investigação publicados. Os ACOs procederam, ainda, ao reencaminhamento dos estudantes que recorreram a métodos de fuga deliberada à deteção, como seja a retroversão ${ }^{15}$.

Voltando aos procedimentos do sistema ACO, assim que o nível (baixo, médio ou elevado) era fixado, o ACO recorria a uma tabela de penalizações em que cada nível surgia associado a determinadas consequências. Com o tempo, o número ótimo de penalizações disponíveis pareceu estabilizar em cinco ou seis e apontar para uma ou duas por nível, com algum grau de sobreposição, o que significa que a mesma penalização podia ser aplicada a níveis de gravidade diferentes. Para ajudar os ACOs a utilizar a tabela de maneira coerente, o acesso ao cargo passava por um processo de formação e de observação dos colegas, pela resolução de casos hipotéticos e pela participação num painel de discussão à porta fechada em que lhes era permitido partilhar questões e trocar pontos de vista a propósito de casos particularmente exigentes. A realização regular de reuniões - pelo menos uma por período letivo - e de conversas do âmbito profissional com especialistas do meio universitário contribuiu, ainda, para a construção de uma abordagem partilhada. Nos casos em que os ACOs funcionaram isoladamente, o fator coerência ressentiu-se (Carroll e Seymour, 2006).

Como passo seguinte, o ACO informa o estudante do resultado, fazendo-lhe o elenco das penalizações e de eventuais novas exigências em matéria de orientação ou de apoio tutorial. Além disso, deverá responder e dar solução a qualquer questão imediata e garantir que o estudante sabe onde e de que forma poderá apresentar recurso. Nesta altura o ACO procede ao registo das decisões, utiliza os procedimentos pertinentes para as comunicar a terceiros - seja o professor que fez

\footnotetext{
15 'Retroversão' designa a prática que consiste em selecionar material para uso indevido, vertê-lo para outra língua por meio de um programa como o Google Tradutor, e voltar depois a vertê-lo para a língua original. A ideia é que o texto daí resultante terá sofrido modificação suficiente para poder 'escapar ao radar' do software de cotejo textual.
} 
a participação inicial ou um painel de examinadores, por exemplo -, e remete o caso para o processo de avaliação normal. Tem então lugar, finalmente, a aplicação das consequências previstas.

Os relatórios anuais elaborados por cada um dos ACOs são fundidos num único documento respeitante a toda a universidade, que passa seguidamente para uma comissão de gestão da qualidade para efeito de análise e avaliação.

\subsection{Conclusão}

Não obstante a sua procupação com o modo de lidar com o plágio estudantil e o ludíbrio, os responsáveis pela definição das políticas e pela direção das instituições nem sempre sabem bem onde começar; alguns nem sequer se mostram dispostos a dar esse passo. Cria-se, assim, uma situação em que os professores se sentem inseguros e desapoiados e em que os estudantes se sentem vítimas injustiçadas por lhes ser imputada a responsabilidade de agir com integridade sem que lhes tenham sido fornecidos os instrumentos e o saber necessários, ao que acresce uma injustificada atribuição de culpa pela prática do ludíbrio ou por a tolerarem a outros. Sutherland-Smith (2010) apela a uma menor "ênfase sistémica na dissuasão e na penalização, [visto que] estas abordagens, só por si, têm um valor educativo questionável. A investigação académica disponível sugere que o plágio é feito de múltiplas camadas e requer toda uma variedade de estratégias dentro de um quadro global de sustentabilidade ética" (p. 13).

O presente texto vai ao encontro desta perspetiva, na medida em que propõe uma ênfase sistemática. Ou seja, ele coloca a tónica numa gestão do plágio estudantil que se deseja centrada na aprendizagem partilhada. Esta é uma causa pela qual vale a pena pugnar em nome dos nossos estudantes e que vale a pena defender com vista à preservação dos valores do estudo universitário e dos graus que ele confere. 


\subsection{Referências bibliográficas}

Ashworth P.; Freewood, M. e Macdonald, R. (2003). The student lifeworld and the meanings of plagiarism. Journal of Phenomenological Psychology, 34(2), pp. 257-278.

Badge, J.; Cann, J. e Scott, J. (2007), To cheat or not to cheat? A trial of the JISC plagiarism detection service with biological science students. Assessment and Evaluation in Higher Education, 32(4), pp. 1-7.

Blum, S. (2007), My Word! Plagiarism and College Culture. Ithaca, NY - USA: Cornell University Press.

Bretag, T.; Mahmud, S.; Wallace, M.; Walker, R.; Green, M.; East, J.; James, C.; McGowan, U. e Partridge, L. (2011), Core elements of exemplary academic integrity policy in Australian higher education. International Journal for Educational Integrity, $7(2)$, pp. 3-12.

Bretag, T.; Mahmud, S.; Wallace, M.; Walker, R.; McGowan, U.; East, J.; Green, M.; Partridge, L. e James, C. (2014), Teach us how to do it properly! An Australian academic integrity student survey. Studies in Higher Education, 39(7), pp. 1150-1169.

Carroll, J. (2005), Handling student plagiarism: moving to mainstream. Brookes eJournal of Learning and Teaching, 2(2).

Carroll, J. (2007), A Handbook for Deterring Plagiarism in Higher Education. Oxford Centre for Staff and Learning Development. Oxford, UK: Oxford Brookes University.

Carroll, J. (no prelo), Tools for Teaching in an Educationally Mobile World. Londres e Nova Iorque: Routledge.

Carroll, J. e Appleton, J. (2005), Towards consistent penalty decisions for breaches of academic regulations in one UK university. The International Journal for Educational Integrity, 1(1).

Carroll, J. e Seymour, D. (2006), The effect of a penalty tariff on consistent decision-making in cases of student plagiarism. Proceedings of the JISC International Plagiarism Conference. Obtido em http://www.jiscpas.ac.uk/2006papers.php Carroll, J. e Zetterling, C-M. (2009), Guiding Students away from Plagiarism / Hjälp studenterna att undvika plagiering, Learning Lab. Stockholm, Sweden: Royal Technical University. 
Davis, M. (2013), The development of source use by international postgraduate students. The Journal of English for Academic Purposes, 12, pp. 125-135.

de Lambert, K. ; Ellen, N. e Taylor, L. (2006), Chalkface challenges: a study of academic dishonesty amongst students in New Zealand tertiary institutions. Assessment and Evaluation in Higher Education, 31(5), pp. 485-503.

Deech, R. (2006), Plagiarism and institutional risk management, Conference for PlagiarismAdvice.org. Obtido em http://plagiarismadvice.org/research-papers/ item/plagiarism-and-institutional-risk-management

Devlin, M. (2006), Policy, preparation, and prevention: Proactive minimization of student plagiarism. Journal of Higher Education Policy and Management, 28, pp. $45-58$.

Fishman, T. (2009), "We know it when we see it" is not good enough: toward a standard definition of plagiarism that transcends theft, fraud, and copyright. $4^{\text {th }}$ Asia Pacific Conference on Educational Integrity (4APCEI) 28-30, setembro, University of Wollongong NSW Australia.

Glendinning, I. (2013), Impact of policies for plagiarism in Higher education across Europe - project results. Obtido em 3 de maio de 2014 em http://ippheae.eu/ project-results.

Gu, Q.; Schweisfurth. M. e Day. C. (2010), Learning and growing in a 'foreign' context: intercultural experiences of international students. Compare, 40(1), pp. 7-23.

Howard, R. (2008), Plagiarizing (from) graduate students. R. M. Howard e A. E. Robillard (Orgs.), Pluralizing plagiarism: Identities, contexts, pedagogies (pp. 92-100). Portsmouth, NH: Boynton/Cook.

Hunt, R. (2004), Whose silverware is this? Promoting plagiarism through pedagogy. JISC Plagiarism Advisory Service Conference, Newcastle-upon-Tyne, UK, 24-28, junho.

Lancaster, T. e Clarke, R. (2007), The phenomena of contract cheating. In T.S Roberts (Org.), Student plagiarism in an online world: Problems and solutions (pp. 144-158). Hershey, PA: Idea Group Inc.

Macdonald, R. e Carroll, J. (2006), Plagiarism - a complex issue requiring a holistic institutional approach. Assessment and Evaluation in Higher Education, 31(2), $233-245$. 
Martin, J. e Haeringen, K. (2011), Can a policy change practice? An evidence-based approach to developing policy. The International Journal for Educational Integrity, 7(2), pp. 13-22.

McCabe, D. (2003), Promoting academic integrity: a US/Canadian perspective. Educational Integrity: plagiarism and other perplexities. First Australasian Educational Integrity conference, 21-22 de novembro, Adelaide, S. Australia. McCabe, D. (2005), Cheating among college and university students: a North American perspective. International Journal for Educational Integrity, 1(1), pp. 1-11.

McGowan, U. (2005), Does educational integrity mean teaching students NOT to 'use their own words'? International Journal for Educational Integrity 1(1).

Neville, C. (2009), International Students, writing and referencing. Referencing and writing symposium. University of Bradford, UK, 9 de junho.

Park, C. (2004), Rebels without a clause: towards an institutional framework for dealing with plagiarism by students. Journal of Further and Higher Education, 28(3), pp. 291-306.

Partridge, L. e West, J. (2003), Plagiarism: perceptions and occurrence amongst transnational students in the Graduate School of Education, University of Western Australia. Educational Integrity: plagiarism and other perplexities, proceedings of the first Australasian Educational Integrity conference, Adelaide, Australia, 21-22, novembro, pp. 149-153.

Sutherland-Smith, W. (2010), Retribution, deterrence and reform: the dilemmas of plagiarism. Journal of Higher Education Policy and Management, 32(1), pp. 5-16.

Tennant, P. e Duggan, F. (2008), Academic Misconduct Benchmarking Research Project: Part 2. The Recorded Incidence of Student Plagiarism and the Penalties Applied. The Higher Education Academy and JISC. Obtido em 27 de abril de 2014 em www.heacademy.ac.uk/assets/York/documents/AMBeR_PartII_Full_Report.pdf Tennant, P. e Rowell, G. (2009-2010), Benchmark Plagiarism Tariff: A benchmark tariff for the application of penalties for student plagiarism in higher education. Relatório no âmbito do projeto AmBer. Obtido em 2 de maio de 2014 em http://www.plagiarismadvice.org/resources/institutional-approaches/item/ tennant-referencetariff 
Walker, J. (2010), Measuring plagiarism: researching what students do, not what they say they do. Studies in Higher Education, 35(1), pp. 41-50.

Whitley, B. e Keith-Spiegel, P. (2002), Academic Dishonesty: an educator's guide. Mahwah, NJ: Lawrence Erlbaum Associates.

WPA/ Council of Writing Program Administrators (2003), Defining and avoiding plagiarism: the WPA statement of best practice'. Obtido em 28 de abril de 2014 em http://wpacouncil.org/positions/WPAplagiarism.pdf.

Yeo, S. e Chien, R. (2007), Evaluation of a process and proforma for making consistent decisions about the seriousness of plagiarism incidents. Quality in Higher Education, 13(2), 187-204. 